FOLIA SCANDINAVICA VOL. 17 POZNAŃ 2015

$\mathrm{DE}$ DE GRUYTER OPEN $\circlearrowleft$

\section{PRESSto.} IMU. Adam Mickiewicz University Repository

\title{
EN ENSOM NORSK GRAV I POZNAŃ. ET POSTSKRIPTUM TIL THE GREAT ESCAPE
}

\author{
TADEUSZ W. LANGE
}

Adam Mickiewicz University, Poznań

ABSTRACT. The article is an account of the life and death of Halldor Espelid, a young Norwegian RAF pilot born in Bergen, trained at "Little Norway" in Canada, shot down over occupied France, put in the POW camp for airmen in Sagan (now Żagań in Poland), arrested near Flensburg while taking part in the so-called Great Escape, and murdered at the age of 24 by the Kiel Gestapo. His body was cremated, his ashes buried at Sagan and later moved to the Old Garrison Cemetery in Poznań, Poland, together with the remains of 47 other participants of the famous Great Escape murdered at Hitler's personal order.

På Old Garrison Cemetery, anlagt i 1925 av den britiske Imperial War Graves Commission i skråningen til Citadellet, et festningsanlegg i utkanten av byen Poznań, finnes det 452 gravstøtter til soldater som enten falt på slagmarken $i$ en av verdenskrigene, eller som døde i fangeleire (Olszewski, 2008:465,468). Det er hovedsaklig briter, men også en del nyzealendere, kanadiere og sørafrikanere.

I et adskilt, stort felt ligger falne krigsflybesetninger som ble skutt ned over det som er dagens Polen, og andre falne flyvere opprinnelig begravet i Polens jord. Blant dem er mlitære fra andre allierte nasjoner som tjenestegjorde i det britiske flyvåpen. Her hviler til og med noen polakker og også gravlundens eneste nordmann, Halldor Espelid.

Urnen med asken hans ble hentet fra byen Żagań (før krigen Sagan) fra tidligere Stalag Luft III, der tyskere holdt allierte flyvere fanget. Men nordmannen døde ikke i krigsfangeleiren der. Hans historie er knyttet til en av 2. verdenskrigs mest spennende episoder og er verd å gjengi $i^{1}$.

\footnotetext{
${ }^{1}$ Visse deler av Halldor Espelids livshistorie er kjent for det allmenne norske publikum fra avisartikler, som regel med en del ukorrekte opplysninger. Flest dokumenterte detaljer finner man i Guhnfeldts bok, naturlig nok med fokus på Espelids militærtjeneste. Utenlandske
} 


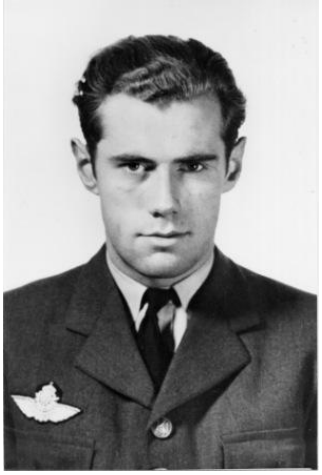

Fot. 1. Halldor Espelid

Halldor Espelid ble født den 6. oktober 1920 på Askøy utenfor Bergen som nest eldst av de fem barna til herredsagronom og forretningsfører Ivar Espelid og lærerinne Gudrid Espelid, født Eidnes. Halldor hadde fire søsken ${ }^{2}$. Han vokste opp på Kleppestø i Askøy kommune. Han gikk først på folkeskole på Kleppe, og i 1935 begynte han på Katedralskolen inne i Bergen. Som de fleste nordmenn da som nå, var han mye utendørs: om sommeren på seteren til sin onkel på Hardangervidda, om vinteren på fjellene rundt Bergen, der han gikk på ski. Han skal ha vært musikalsk begavet og spilte orgel mer enn brukbart

Etter tyskernes angrep på Norge deltok Halldor Espelid aktivt i Sivilforsvaret. Den 16. september 1940, 20 år gammel, avbrøt han skolegangen på «Katten» i gymnasets siste år og sammen med to skolekamerater - i likhet med hundrevis av andre unge landsmenn rømte til Shetland. De og fem andre dro med fiskeskøyta «Traust» fra Solund ${ }^{3}$.

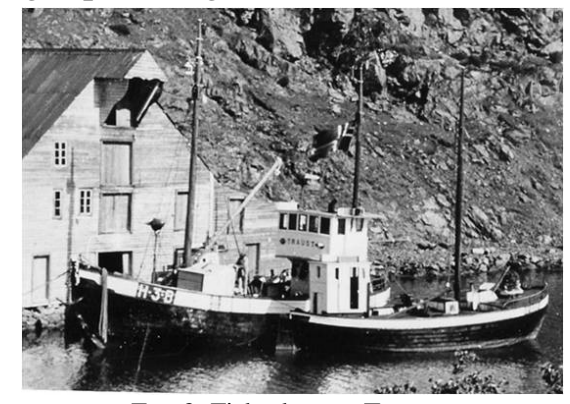

Fot. 2. Fiskeskøyta «Traust»

Fra Shetland kom han seg så til Skottland for å slutte seg til norske styrker der. Ettersom han ville fly, meldte han seg til Hærens Flygevåpen, og $\mathrm{i}$ begynnelsen av 1941 ble han sendt til Canada. Det er sannsynlig at han seilte dit ombord båten som het «Ørnefjell», og allerede da ble kjent med Nils Jørgen Fuglesang fra Florø, som seilte med den ${ }^{4}$, og som Espelid senere delte skjebne med.

Halldor Espelids opplæring og senere tjeneste er godt kjent takket være flyverloggbøkene hans oppbevart på Forsvarsmuseet i Oslo.

beretninger, hvorav den første (og mest kjente) er Brickhills The Great Escape, utgitt på norsk som Flukten fra Stalag Luft III (i 1951 og 1955) nevner ham så vidt; ofte - som f.eks. i eldre polske bøker (av Sojka (1975) og Szubański (1987)) og til og med i de nyeste engelsk-språklige (av Read (2012) og Walters (2013)) - nevnes han under det ukorrekte fornavnet Hallada.

${ }^{2}$ blant disse Ingrid Espelid, senere kjent fra NRKs TV-Kjøkkenet og gift med den internasjonalt kjente arkitekten Jan Inge Hovig, og Mons Espelid (senere stortingsrepresentant for Hordaland).

${ }^{3}$ (Ulstein, 2011:419), http://www.warsailors.com/shetlandbus/boats.html (hentet mars 2015).

${ }^{4}$ Etter Nils Fuglesangs dagbok, sitert av Brigitte H. Myhre i hennes særoppgave 199798, kopi hos forfatteren. 
Etter å ha fullført opplæring i Canada på Flyvåpnenes Treningsleir (bedre kjent som «Little Norway») på Hærens flyverkull nr.1 sammen med bl.a. Nils Fuglesang, der han lærte å fly et skolefly ${ }^{5}$, fullførte han i likhet med de andre trening på Moose Jaw. Her fløy han et annet skolefly ${ }^{6}$ og her, ifølge Gunhfeldt (ibidem), mottok han flyvervingen 21. november 1941. Senere, ved Island Airport (Toronto) lærte han også å fly et bombejagerfly ${ }^{7}$.

I mars 1942 seilte han til Storbritannia for å delta i krigen, og havnet først på RAF-statsjonen Ternhill i Shropshire ${ }^{8}$, der han lærte å fly et «ekte» jagerfly ${ }^{9}$,

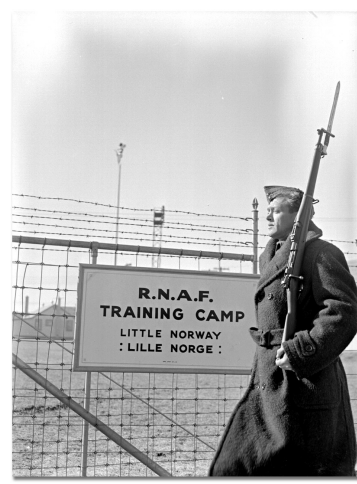

Fot. 3. Little Norway og deretter ved No.58 Operational Training Unit i Grangemouth, Skottland, der han i to måneder fløy britiske Miles Master Mk. III-fly. Etter denne siste opptreningen begynte han 14. juli tjenesten som jagerpilot med sersjants grad i den norske 331 RAF Skvadron i North Weald, Essex, der han endelig begynte å fly Supermarine Spitfire-maskiner ${ }^{10}$.

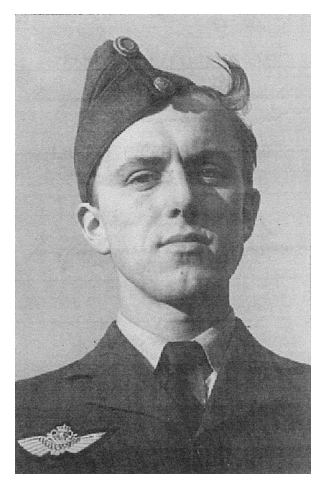

Fot. 4. Nils Fuglesang

Nils Fuglesang havnet i den andre norske skvadronen stasjonert der, 332. Espelid var med ${ }^{11}$ på det sjebnesvangre toktet 31. juli (kodenavnet Rodeo), der Fuglesangs skvadron mistet fire fly. Han rakk såvidt å delta $\mathrm{i}$ Diepperaidet (Operation Jubilee) 19. august med et nesten to-timers tokt ${ }^{12}$, var med på attack on ground targets fire dager senere ${ }^{13}$, men fikk ikke kjempe så mye lenger. I loggboken hans ved datoen 27. august står det megetsigende ordet MISSING. Under et tokt (kodenavnet

f. Roadstead) den dagen ble nemlig hans Spitfire $^{14}$ truffet av tysk luftvern over

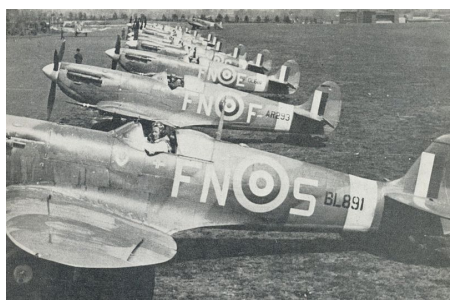

Fot. 5 Spitfire-flyene i Skvadron 301 Frankrike, ikke langt fra Dunkerque.

${ }^{5}$ av typen Fairchild (M-62, også kjent som PT-19 Cornell).

${ }^{6}$ Harvard Mk II.

${ }^{7}$ Douglas (A-33, d.v.s. Northrop A-17).

${ }^{8}$ ved No 5 Advanced Flying Unit.

${ }^{9}$ av typen Curtiss P-36 Hawk.

${ }^{10}$ først av eldre type Mk. I og Mk. II, og så nyere Mk.V.

${ }^{11}$ Han fløy da Spitfire FN-F/AR293.

${ }^{12}$ Han fløy da Spitfire FN-D/AD373.

${ }^{13}$ Hans Spitfire merket FN-J var da sannsynligvis utstyrt med cine-gun kamera.

${ }^{14} \mathrm{Mk}$. Vb med nummer FN-A/AR343. 
Hans kamerat Bjørn Ræder skrev i sin dagbok følgende om denne hendelsen:

Han blev sett truffet av flak over Abbéville i 20000 feet hvorefter maskinen divet ut av formasjonen. Imidlertid, litt senere, kom han op tilbake til formasjonen igjen. Ennu et par minutter, og han brøt ut og fortsatte innover Frankrike. Hans radio måtte ha gått i stykker og hans manøvrering var helt uforståelig (etter Guhnfeldt, ibidem).

Sersjant Espelid ble tatt til fange av tyskerne og ført til Stalag Luft III, en fangeleir for flygende mannskaper, drevet av Luftwaffe i tyske Sagan.

En norsk medfange, Jens Müller ${ }^{15}$ (fra hans skvadron, skutt ned ved den belgiske kysten før Espelid begynte sin tjeneste i den), skrev senere i sine erindringer:

Noen dager etter kom et nytt parti med fanger, og blant dem en nordmann. Hal[1]dor het han, og var fra Bergen. Ett av de koseligste mennesker jeg har truffet. Vi gikk runder sammen, og glemte tid og sted, mens vi pratet om felles kjente, om hjemlandet og om fremtiden. [...] Dessverre ble ikke Hal[1]dor lenge i leiren. Tyskerne hadde en leir i Polen, Schübien ${ }^{16}$, som for en del skulle fylles med fanger fra Stalag Luft III. Haldor var blant dem som måtte dra (Müller, 1946:77f.).

Ikke for godt, viste det seg, for de norske som da var blitt flyttet, kom tilbake etter en stund. Da hadde situasjonen på Stalag Luft III forandret seg: leiren var blitt vesentlig utvidet og de allierte flyverne omplassert til den nye delen. I mai 1943 dukket Espelids gamle kamerat Nils Fuglesang opp i leiren. Den 2. mai var hans Spitfire blitt skutt ned av en Focke-Wulf under et tokt over Holland ${ }^{17}$.

Leire som Stalag Luft III ble drevet i henhold til Genèvekonvensjonen, som ga krigsfangene en viss bevegelsesfrihet. Fangene hadde anledning til å drive idrett og de hadde eget bibliotek og teater. Røde Kors sørget for at de ikke sultet og at de fikk utvekslet brev med sine nærmeste. Mot slutten av 1943 begynnelsen av 1944 fikk Halldor Espelid sendt noen brev hjem til familien i Norge. Dessuten skrev han til Joy Bell, en venninne han hadde etterlatt i Moose Jaw, Canada (Guhnfeldt, 2009:244).

Siden forholdene i leiren ikke var så veldig strenge, var det mulig å arrangere fluktforsøk. Dette benyttet mange fanger seg av, både individuelt og gruppevis, men uten hell. I den nye leiren, derimot, ble alle forsøkene på å flykte koordinert av en fluktkomité, ledet av «Big X». Denne var Squadron Leader Roger J. Bushell, en erfaren flyktning fra forskjellige krigsleire fra før ${ }^{18}$.

15 Jens Einar Müller, født i 1917. Løytnant fra 331 skvadron, skutt ned 19. juni 1942. Forfatter til boken om sine krigserfaringer og Den store flukten. Knyttet til luftfart hele sitt liv. Gikk av med pension som ansatt i SAS. Døde i 1999.

${ }^{16}$ Egentlig Schubin, nå Szubin i nærheten av Bydgoszcz, Polen; Offizierlager XXI-B der var opprinnelig bygget for franske offiserer etter Frankrikes fall i 1940.

${ }^{17}$ Spitfire Mark IX, BS540, merket AH-E. Han mavelandet at Kortgene, Frederikspolder.

${ }^{18}$ Hovedskikkelse i Brickhills bok. Jurist av yrke, født i Sør-Afrika, skudd ned over Belgia i mai 1940, Bushell hadde rømt først fra Oberursel Dulag Luft leir i juni 1941, og en gang til under transport 
Omtrent 600 fanger ble engasjert i forberedelsene til det som senere ble kjent som The Great Escape, etter en bok av eksfange fra Sagan Paul Brickhill (1951), filmatisert i 1963 med samme tittelen ${ }^{19}$. Tre lange, dyptliggende tunneler ble gravd samtidig, fordi man regnet med at i hvert fall én ville bli oppdaget og tyskernes oppmerksomhet følgelig avledet. Alle som deltok i rømningsarbeidet ble anvist en avdeling de skulle arbeide ved, avhengig av de enkeltes erfaring og evner. Det var grupper med tunnelgravere, sandbærere, snekkere, vakter, skreddere, dokumentfalsknere osv. Samtlige nordmenn var engasjert $i$ forskjellige avdelinger. Halldor Espelid skal ha vært $i$ etterretningsavdelingen, sammen med en nyzealander av dansk avstamning Arnold Christensen. De to var angivelig ansvarlige for innsamlingen av nyttige opplysninger om forholdene i de skandinaviske land (Carrol, 2004:118,147).

Man regnet med at ca. 200 fanger hadde sjansen til å rømme; en del ble håndplukket blant de mest aktive i planleggingen av flukten ${ }^{20}$. Øvrige navn fikk bli med på loddtrekning fra en blikkboks. Halldor Espelid og tre andre nordmenn var blant de heldige. De skulle rømme parvis.

Den store flukten begynte natten til 25. mars 1944. Dessverre, tunnelen på over $100 \mathrm{~m}$ viste seg å være litt for kort og ble oppdaget av tyskerne etter at bare 76 fanger (fra 13 forskjellige nasjonaliteter) hadde rømt. De norske var blant dem.

Ovennevnte Jens Müller og hans kamerat, Per Bergsland $^{21}$, rømte nordover via Küstrin (i dag Kostrzyń) og omsider nådde de havnebyen Stettin (nå Szczecin). Etter mye fram og tilbake traff de der en svensk sjømann, som smuglet dem om bord på et svensk skip. De seilte over Østersjøen, og fra Sverige ble de fløyet til Storbritannia og senere til «Little Norway» i Canada.

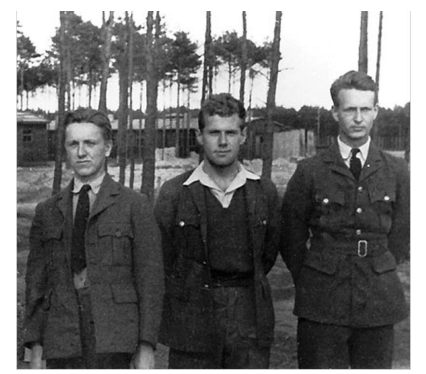

Fot. 6. De norske fangene Bergsland, Espelid, Müller i Sagan

til Warburg i oktober. Han ble arrestert i Praha nesten ett år senere i den store jakten etter Heydrichs likvidasjon.

19 av John Sturges med bl.a. Steve McQueen. I 1988 en slags TV-oppfølger ble laget i USA under tittelen The Great Escape II: The Untold Story.

${ }^{20}$ I sine erindringer sa RAF-pilot Bertram A. James: The first 30 were specially selected by Roger as the most likely to get home on the grounds of language and so on and so there were a number of foreigners among them... A lot of them had been out before and had also done an enormous amount of work on the tunnel. This first group of thirty were chosen and all had suits, papers and money, so that they would be fully equipped to travel hundreds of miles across Germany into neutral territory... The next 70 also had these considerations but they also considered the work they had done for the organisation. (http://www.pegasusarchive. org/pow/jimmy james.htm, hentet mars 2015).

${ }^{21}$ Per Bergsland, født i 1918. Sersjant fra 332 skvadron, skutt ned under Diepperaidet. For å spare familien i Norge for tyske represalier, i fangeskapet oppga seg som engelskmann med navnet Peter Rockland. Knyttet til luftfart hele sitt liv. Gikk av med pension som administrerende direktør i Widerøe. Døde i 1992. 


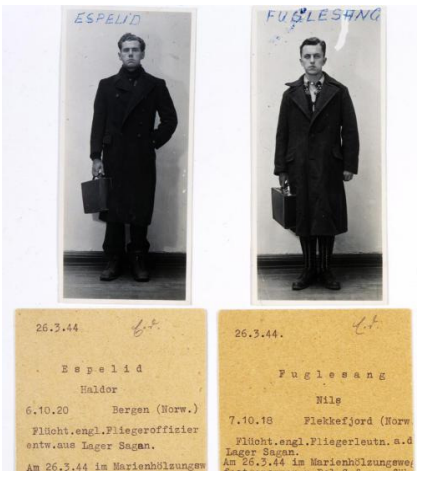

Fot. 7. Espelid og Fuglesang fotografert av Kiel politi etter pågripelsen

Halldor Espelid og hans gamle kamerat Nils Fuglesang ${ }^{22}$ var ikke så heldige. Via Berlin nådde de Flensburg og skulle over grensen til Danmark, da de den 26. mars ble tatt av Kripo.

Alle unntatt Müller, Bergsland og en hollender, van der $\mathrm{Stok}^{23}$, ble arrestert til slutt. Det regnes med at ca. 70000 tyske politifolk og soldater måtte engasjeres $\mathrm{i}$ den storstilte leteaksjonen etter rømlingene. Slik Brickhill (1951:234f.) beretter det, skal en rasende Hitler ha beordret alle henrettet, men senere delvis endret sin ordre, angivelig overtalt av Göring.

Hermann Göring var blant annet sjef for Tysklands flyvåpen, og fryktet kanskje represalier mot egne flymannskaper i alliert fangenskap. RSHAsjef Kaltenbrunner utstedte den såkalte Sagan-Befehl ${ }^{24}$. Ifølge denne ble en liste laget med 50 navn på dem som skulle skytes «under fluktfors $ø k »$ til eksempel for andre. Espelid og Fuglesang stod på denne listen sammen med alle andre som ikke var fra Samveldet av nasjoner.

Omstendighetene omkring deres henrettelse er godt kjent ${ }^{25}$. Den 29. mars, etter ordre fra Gestaposjefen i Kiel, SS-Sturmbannführer Friedrich Schmidt, kjørte hans nestkomanderende, SS-Sturmbannführer Johannes Post og dennes underordnede til Flensburg. De forhørte fangene og overtok dem fra Kripo. De to norske og en rømling til, dansk-nyzealanderen Arnold Christensen, ble satt $\mathrm{i}$ en lastebil og kjørt til utkanten av den lille landsbyen Rotenhahn litt sørvest for Kiel. Der stoppet bilen, og fangene ble beordret ut på marken og skutt ned bakfra. Mordene ble utført av Post og to andre Gestapo-menn: SS-Obersturmführer Oskar Schmidt og SS-Oberscharführer Walter Jacobs.

${ }^{22}$ I følge Barrris (2012:164) skulle Espelid opprinnelig rømme sammen med kanadieren Dick Bartlett, som ble erstattet av Fuglesang noen uker før flukten.

${ }^{23}$ Bram van der Stok, født i 1915. Fra RAF skvadron 41/91. Skutt ned 12. april 1942 over Frankrike. Under Den store flukten fikk hjelp av den hollandske hjemmefronten og kom seg til Gibraltar. Den mest dekorerte flyveren i hollandsk historie, nektet å ta kommandoen over Det hollandske luftforsvaret etter krigen. Flyttet til USA, jobbet bl.a. i NASA og US Coast Guard. Forfatter av en bok om sine krigserfaringer og Den store flukten. Døde i 1993.

${ }^{24}$ Er ikke blitt bevart, men er siden blitt rekonstruert slik: "Nach der Vernehmung sind die Gefangenen gemäß der durch den Chef der Kriminapolizei Nebe und den Chef der geheimen Staatspolizei Müller erstellten Namensliste in Richtung des Mutterlagers abzutransportieren und unterwegs zu erschießen. Man soll das mit einen Fluchtversuch oder geleisteten Widerstand bergründen. Niemand von den sich auf der Liste befindlichen Personen kann verwundet sein oder sich retten" (etter Sojka, 1975). Brickhill (1951:235f.) oppgir innholdet annerledes og lite troverdig.

${ }^{25}$ Case no 62: s. 42-44. 
Nordmennene ble straks kremert ${ }^{26}$ i Kiel, og urnene med navn på brakt tilbake til Stalag Luft III hvor de ble begravet sammen med alle de andre som var blitt henrettet. Her reiste også medfangene et monument over de 50, hvor asken ble gravlagt. Monumentet står fortsatt i Żagań.

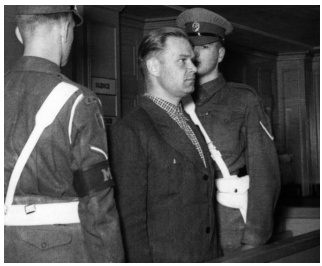

Fot. 8. Johannes Post i retten

Det britiske flyvåpenet glemte ikke krigsforbrytelsen. En spesiell enhet ble avsatt like etter krigen med det formål å oppspore alle nazi-forbryterne knyttet til mordene. I 1947 ble en del av dem stilt for den britiske militærretten i Hamburg. 14 ble hengt, deriblant SS-mennene Post, O. Schmidt og Jacobs ${ }^{27}$.

I 1949 i samarbeid med britiske myndigheter ble urnene flyttet til den ovennevnte krigskirkegården i Poznań, men ikke alle: én var blitt satt ned i Berlin, og en annen, som inneholdt asken til Nils Fuglesang, ble senere sendt til hans mor og gravlagt i Rasvåg på Hidra i Flekkefjord, der mange av forfedrene hans også hviler $^{28}$.

Gravstøtten over Halldor Espelid står nå blant de 47 øvrige ofrene fra den mislykkede rømningen, to meter fra gravstenen til Roger Bushell, hjernen bak Den store flukten.

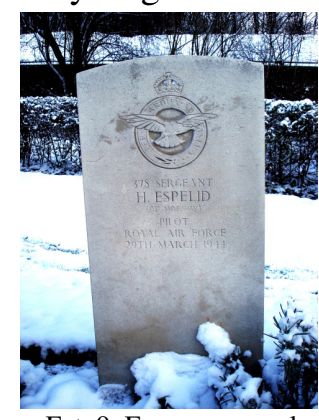

Fot. 9. En ensom norsk grav i Poznań

\section{REFERANSER}

Barris, T. (2012). The Great Escape. A Canadian Story. Durdun Press.

Brickhill, P. (1951) Flukten fra Stalag Luft III. Oslo: Nasjonalforlaget. Oprinnelig:

(1951). The Great Escape. London.

Carrol, T. (2004). The Great Escape from Stalag Luft III. New York.

Guhnfeldt, C. (2009). Spitfire Saga, II. Oslo: Wings.

Müller, J. (1946). Tre som kom tilbake, Oslo: Gyldendal.

${ }^{26}$ Som alle de andre myrdede rømlingene. Hensikten var å skjule spor etter henrettelsen, muligens også for å forenkle transporten tilbake til Stalag Luft III.

${ }^{27}$ I 1968 ble også Friedrich Schmidt stilt for retten, men det politiske klimaet var da annerledes og han slapp med dom på 2-års fengsel som han aldri sonet. Saken ble kjent i Norge, der pressen i sin omtale brukte overskriften «Krigsbøddel får mini-straff og slippes fri av helsegrunner».

${ }^{28}$ I en e-post sendt til forfatteren av Christine Connerty ved Commonwealth War Graves Commission heter det: "According to an RAF report held by us, for some unknown reason, a former GAF guard (Erwin Kujath) at Stalag Luft III admitted to removing Fuglesang's urn after the war. He handed it over to the RAF authorities in Berlin in August 1945. It was then held in the RAF Station Church for a year and then buried in Berlin 1939-45 War Cemetery. However, in December 1947 the urn was exhumed and handed over to the Norwegian authorities for return to Norway." 
Olszewski,W. (2008). Cmentarze na stokach poznańskiej Cytadeli. Poznań: Wyd. UAM.

Read, S. (2012). Human Game: Hunting the Great Escape Murderers. Penguin U.S. Sojka, T. (1975). Sagan-Befehl. Warszawa 1975.

Szubański, R. (1987). Pięćdziesięciu z Żagania. Warszawa: Książka i Wiedza.

Ulstein, R. (2011). Englandsfarten. Bind 2: søkelys mot Bergen. Nova.

Walters, G. (2013) The Real Great Escape. Bantam.

Case no 62: Trial of Max Wielen and 17 others; the Stalag Luft III case. In: LawReports of Trials of War Criminals, The United Nations War Crimes

Commission, Vol. XI 1949, London: HMSO.

\title{
ONLINE RESSURSER
}

http://www.pegasusarchive.org/pow/jimmy_james.htm

http://www.warsailors.com/shetlandbus/boatst.html

\section{BILDER HENTET FRA}

Fot. 1 RAF; Guhnfeldt, 2009:243.

Fot. 2. Hentet fra Internett, ikke tilgjengelig lenger.

Fot. 3. Familiearkiv, hentet fra særoppgave av familemedlem Birgitte H. Myhre (1997/98). Fot. 4. Archives of Ontario, C 109-2-0-18.

Fot. 5. Tvedte, J. (1958-1960). Flyvningen. Det moderne eventyr. Oslo:Norsk fagliterattur. Fot. 6. University of Western Ontario

Fot. 7. British National Archives.

Fot. 8. John Topham $\dagger$, Mail Online.

Fot. 9. Bilde tatt av forfatteren.

\author{
Tadeusz W. Lange \\ Uniwersytet im. Adama Mickiewicza w Poznaniu \\ Katedra Skandynawistyki \\ Collegium Novum \\ al. Niepodległości 4 \\ 61-874 Poznań \\ Poland \\ twlange@amu.edu.pl
}

